\title{
Theoretical issues related to the impact of research and development expenditures on the growth of the firm
}

\author{
Darina Pavlova ${ }^{1}$ \\ 1-Technical University of Varna, Department of Industrial Management, 9010, 1 Studentska Street, Varna, Bulgaria \\ Corresponding author contact: pavlovadetu-varna.bg
}

\begin{abstract}
The substitution of capital for knowledge as the main source of progress is the basis for the development of a "knowledge-based economy". Research and development $(R \& D)$ is one of the means by which the availability of new knowledge can be increased in an organized manner. The paper, therefore, enquires into such issues as the impact of research and development $(R \& D)$ expenditures on the firm's growth. Brought into focus is the fact that the level of innovation adoption of other firms is not completely an exogenous variable but is directly related to the $R \& D$ expenditures incurred by the firm itself. Accordingly, the assumption that the level of innovation adoption is to some extent an endogenous process is brought to the fore.
\end{abstract}

Keywords: Technologies, Innovation, R\&D expenditures, Growth of the firm

\section{$1 \quad$ Introduction}

At the current stage of the socio-economic development observed is a major trend of transformation of today's economy and society to a knowledge-based economy and society that rely heavily upon application of knowledge. Such a shift implies conversion of knowledge and information into a fundamental resource. Brought forth is an economy that is being built upon novel information technologies essential sources for future economic growth.

The rapid development of knowledge-based economy, thoroughly interpreted over the last few years and profoundly restated in the research work of various foreign economists, brings the process of creating innovation and new knowledge into the principal focus of the scientific interest. Research and development (R\&D) activity is one of the tools that can enhance the innovation activities of firms and determine the effectiveness of the new knowledge.

\section{Main theories and key growth factors}

It was John Kenneth Galbraith in the early 60 s of the $20^{\text {th }}$ century (1952) who pointed out that "the era of cheap innovation" was brought to an end. He argues that the firms having exhausted the lowcost research and development programmes are now forced to make R\&D efforts. The aim is to reach a level of the scientific and technical progress, that would directly result in - achieving and/or maintaining market power. Thus, indirectly posed is the issue associated with the causes and potential longrun consequences of the economic growth over time.

Growth in the traditional theories is referred to as a process of accumulation of (physical) capital in time with a particular technology ""taking up" the capital and labour to manufacture output final goods. Through reinvestment of part of the production (valued by the capital turnover in the form of profit), the capital mass increases, leading to considerable growth of output produced per capita. Growth rates above those, which are the result of the utilization of capital and labor resources, are then explained as related to exogenous changes in technology, i.e. to changes in the benchmark at which capital and labor convert materials into finished goods. This growth is defined as residual -commonly called the "Solow residual" (Solow, R.M., 1956) and is taken as equivalent to the degree of the nonmaterial technical change in the economy over the surveyed period. Solow's assessment of the residue leads to the conclusion that most of the observed growth in the US economy is due to a technical 
change. A conclusion is reached that a growth projection is possible only if advances in technical progress are implemented on a regular basis.

From the 50 s to the 80 s of the last century in the study of the economic growth applied primarily was the neoclassical model and more precisely- the concept of production function. It expresses in mathematical terms the dependency between the maximum volume of production and a combination of factors determining it at a given level of knowledge and technology.

In the $80 \mathrm{~s}$ and $90 \mathrm{~s}$ the growth theory is put again on the agenda, and this time the emphasis is on modeling of technical change (initially treated as an exogenous factor), which is to explain the existing growth projection. As one of the decisive factors for economic growth as well as with the purpose of obtaining a better insight into the causes and consequences of the technological change, in the subsequent studies it is regarded largely as an endogenous process as well. Consequently, the dependency of the new technologies on $\mathrm{R} \& \mathrm{D}$ expenditures, investment decisions, and economic policy was more clearly defined.

Examined in the literature are mainly two principal types of technological change:

- The first type relates to the increase in the number of innovative technologies and here the major contributions were made by Romer, Grossman and Helpman (Romer, 1990), (Grossman, 1991).

- The second type of technological change refers to qualitative improvement of existing technologies, with the basic postulates being developed by Aghion, Howitt (Aghion,P. and Howitt, P. 1992), Grossman and Helpman (Grossman, G.M. \& Helpman, E. (1991).

The first type of technological change might be compared, with regard to its results, to product innovation or total (overall) technological change. As for the second type of technological change, quality improvement of existing technologies, it can be virtually identified with a process innovation or partial technological change.

The underlying fundamental concept of technological change by increasing the number of technologies is initially introduced by Paul Romer. Known also as the Romer model, it views the technological change in the context of the growth theory. This particular model is widely recognized as a standard reference work in the literature on R\&D and innovations: it considers innovation activities as public goods (i.e. the presence of positive external factors associated with accumulation of capital). As components in Romer's model of technological change involved are three factors: human capital $(L)$, physical capital $(C)$ and the level of existing technology $(T)$. In the model, the human factor is envisaged as a rival good in view of the fact that its application in the work of a single economic entity, excludes the possibility of its simultaneous use by another entity. On the other hand, the technology is considered non-competitive, because its use by one firm in no way limits its use by another firm. The human capital can be used both for the production of the final goods $(Y)$, and for the generation of new technologies. New technologies in R\&D are generated using human capital and the stock of accumulated knowledge. Pursuing a similar train or succession of thoughts Romer reached the following equation for the generation of technologies:

$$
\frac{d T}{d t}=\delta \cdot v \cdot L \cdot T
$$

where: $v$ is part of the total stock of human capital, employed by R\&D sector; $\delta$ - parameter of productivity.

It should be noted that in the Equation (1) the constant value of $v . L$ means that the very growth rate remains constant. Furthermore, essential characteristic feature of the research sector is its human, capital and technological intensity. Yet, the physical capital $(C)$ is not a constituent part or component of the technology equation-it should be used only in the production of final goods:

$$
Y=[(1-v) L]^{\alpha} \cdot \sum_{i=1}^{A}\left(x_{i}\right)^{1-\alpha}
$$

where: $x_{i}$ represents the magnitude of capital by type $i$.

The production function presented above is of type Cobb-Douglas. With it the parameters (exponents) are assessed through direct use of empirical data. In this way, determined is the extent to which each of the factors is involved in the overall increase of the production being manufactured. In this 
example, the total exponential sum is 1 and the production function has the following characteristic features:

- It indicates a constant rate of returns to scale. This suggests that an increase in the amount of input labor and capital as a result of a certain factor $\mathrm{k}$ leads to an equivalent increase in the output with the magnitude of that factor $\mathrm{k}$;

- It expresses diminishing returns to a single factor. This means that if we keep, for example, the magnitude of capital $(C)$ constant, the marginal production volume growth would eventually become smaller and smaller with the addition of every other unit of labour $(L)$. The production in formula (2) is represented as an additive function of different types of capital goods, each of them is being built in accordance with a different detailed plan $x_{i}$ for further strategic activities. Thus, taking the population as a constant at a specific point in time (i.e.zero growth of human capital), Romer proposes the following formulation of the production function, inclusive of the technological change:

$$
Y=[(1-v) L]^{\alpha} \cdot C^{1-\alpha} \cdot T^{\alpha}
$$

The second approach to modelling of technological change is for it to be treated as a quality improvement of a constant number of already existing technologies. It has already been stated that this approach was initially advanced by Aghion, Howitt, Grossman and Helpman. It, however, later appears in a more generalized form in Barro, and Sala-i-Martin (Barro, R.J., Sala-i-Martin, X. 1995). They assert that the primary source for enhancing the quality is the usage or employment of the human capital. By analogy with the previous statement, the entire stock of human capital is divided between the production of final goods and the generation of technological changes. Further modifications were introduced to the production function discussed above so as to provide for the qualitative changes in technologies as well:

$$
Y=[(1-v) L]^{\alpha} \cdot \sum_{i=1}^{T}\left(q \cdot x_{i}\right)^{1-\alpha}
$$

The number of technologies, $T$, in the production function hitherto presented remains constant. Special mention should also be made of the fact that a single improvement in the quality, $q$, increases the overall efficiency and effectiveness of all projects (or factors of production), $x_{i}$, and therefore, it leads to an increase in the total production output, $Y$. Applying the above reasoning to the production function in question, and making any necessary modifications, so as to allow for all the individual factors of production (or projects), $x_{i}$ to be replaced with a single expression of $q, T$ and $C$ :

$$
Y=[(1-v) L]^{\alpha} \cdot \sum_{i=1}^{T}(q \cdot C)^{1-\alpha} \cdot T^{\alpha}
$$

The driving force of the production growth is now the efforts to enhance the quality of the existing technologies, rather than the increase in the number of technologies as expressed in Equation (1). Accordingly, the corresponding equation for generation of technology can be written as follows:

$$
\frac{d q}{d t}=\delta \cdot v \cdot L \cdot q
$$

Given the discussion in the previous section, it might be assumed that the only factor that is crucial for the improvement of already existing technologies is the human capital. The human capital is yet a variable factor, having a powerful effect on the scale in the sense that that a single exogenous increase in the human capital stock heightens the growth rate due to improved qualitative results.

On this basis it can be summarized that the macroeconomic approaches to modelling and generation of technological change examined previously in the paper will not be very useful for the purposes of implementing technological change in a separate economic unit. The first steps towards developing a theoretical framework at the level of a microunit were taken by Brander, Spencer and Spence (Brander and Spencer, 1983; Spence, 1984). But a more considerable progress towards deeper understanding of R\&D expenditures and the growth of the firm was achieved by D'Aspremont, C., Jacquemin, A. (1988), who developed a two-stage Cournot duopoly game for the R\&D expenditures and product market competition. Most theoretical developments, however, generally presume that the boundary to which firms can acquire knowledge is determined exogenously (i.e. by external factors). Kamien and Zang (2000) changed the hitherto existing paradigm and argued that the firm's boundary 
for acquiring knowledge is a function of their own efforts for innovation initiatives. In short, market demand modelling is done prior to $R \& D$ production function modelling.

Most research studies of the subject focus primarily on examining the process (technological) innovation. It is further accepted (to make the model less complicated) that R\&D is carried out within Cournot's oligopoly model with possible exogenous "transfusions (transfer)". Under such conditions, market demand modelling is limited to two present on the market uniproduct firms which manufacture products $i$ and $j$ respectively. It should be pointed out that retrospectively A. Cournot was the first pioneer economist to establish the demand equation $(D=f(p))$. Yet in developing his duopoly models he invariably makes use of its inverse function $(p=f(D))$. It should be borne in mind, however, that such an approach is correct only in terms of the functional, but not causal dependence. Nevertheless, this approach is widely used after Cournot and to the present because the price is a direct component of the income of every economic unit.

Given the above, it is assumed that the market demand is of linear dependence and is represented by:

$$
p_{i}=1-b \sigma q_{j}-b q_{i}
$$

where: $p_{i}$ is the price of the product $i$ of the firm; $q_{i}\left(q_{j}\right)$ stands for the amount of the product $i(j)$.

The parameter $\boldsymbol{\sigma}$ is a measure for the interchangeability of the two products (goods), with $\sigma \in[0,1]$. When $\sigma=1$, the two goods are absolutely interchangeable (goods-perfect substitutes), while with $\sigma=$ 0 , the two goods are complimentary (perfect complements) (in the case of monopoly). The multiplier $b$ gives the inverse market demand, expressed by the number of companies against the number of customers.

Following the pure traditional models of cooperation in R\&D the market structure is modelled as a Cournot game, where firms can lower their production costs by R\&D managing (controlling). R\&D efforts not only contribute to reducing the firm's own production costs, but also affect the respective competitors, customers and suppliers. Nonetheless, those firms that implement R\&D activities have the ability to control the cost of research and development in collaboration with other firms. In this case it is assumed that the R\&D results shall then be considered as fully shared. Conducting R\&D in collaboration, make it possible for the firms to take the external parameters associated with the process of R\&D as internal ones. The model of determining R\&D offered here is insufficient for the complete coverage of the real innovation processes being accompanied by risks and irreversible processes.

The major assumptions as regards the production techniques, accessibility of R\&D results, their sharing and R\&D product functions are briefly outlined in the statement below. Manufacturing conditions are represented by the cost function $k_{i}$. Controlling their R\&D activities, the firms can decrease their marginal costs. Denoting $X_{i}$ as an effective R\&D level (the firm's own R\&D and R\&D results obtained from other firms) of a given firm $i$, the cost function (production per unit) of the firm $i$ is presumed to be given by:

$$
k_{i}=c_{i}-f\left(X_{i}\right)
$$

where: $f\left(X_{i}\right)$ is the R\&D production function of the process innovation and $c_{i}$ constitutes the fixed costs.

The cost function (8) is a unit costs determined in monetary units. The restrictive conditions are as follows:

$$
\begin{gathered}
f(0)=0, f\left(X_{i}\right)<c_{i}, f^{\prime}\left(X_{i}\right)>0, \\
f^{\prime \prime}\left(X_{i}\right)<0, \lim _{x_{i} \rightarrow \infty} f^{\prime}\left(X_{i}\right) \rightarrow 0, \\
\left(1-k_{i}\right) \cdot f^{\prime \prime}\left(X_{i}\right)+f^{\prime}\left(X_{i}\right)^{2}<0 .
\end{gathered}
$$

These assumptions ensure that for a process of innovation to take place properly aligned investments should be made in $R \& D$, production costs should be positive, the $R \& D$ production function is increasing and is concave with effective $\mathrm{R} \& \mathrm{D}$, the $\mathrm{R} \& \mathrm{D}$ marginal productivity tends to zero while the effective R\&D approaches infinity and that R\&D expenditure curve has a much steeper slope of increase than the $R \& D$ revenues (returns), so that the condition for the firms not to invest infinitely in $\mathrm{R} \& \mathrm{D}$ is secured. 
In the research analysis advanced by Kamien and Zang, the effective R\&D of a given firm $i,\left(X_{i}\right)$, is directly proportional to the firm's own R\&D xi and to the R\&D investigations received by the firm $i$ from another firm. Both the effective, and the own R\&D are measured in monetary units. The effective $\mathrm{R} \& \mathrm{D}$ is represented through:

$$
X_{i}=x_{i}+(1-\delta) \beta x_{i}^{\delta} x_{j}^{1-\delta}
$$

where: $\delta, \beta \in[0,1]$.

The Equation (10) shows that if a given firm $i$ never invests in R\&D, it then should not get a "transfer" of R\&D results, obtained from the research efforts of other firms.

The parameter $\delta$ refers to the exogenously given intensity of "transfer" of R\&D results. It may just as well have been interpreted as, for example, a parameter, giving the level of patent protection. When $\beta=0$, patents protect research works perfectly well. But when/If $\beta=1$, patents are completely unable to protect research works ( $R \& D$ results). Therefore $\beta$ reflects the restricted ability to protect the results of R\&D.

The parameter $\delta$ shows "the approach to R\&D" of a given firm $i$ (Kamien, 2000, p.998). Thus, if $\delta$ $=0$, then the firms are both universal recipients (beneficiaries) of, and universal donors to, research efforts of other firms ("general R\&D approach"). In that case the effective R\&D function of a given firm $i$ is simplified to the standard effective R\&D (D'Aspremont, C., Jacquemin, A.,1988) formulation as regards the duopoly models,

$$
X_{i}=x_{i}+\beta \cdot x_{j}
$$

At the another extreme, when $\delta=1$, the effective R\&D equals the firm's own R\&D. Then the firms shall not be able to absorb any knowledge from the other firms, nor shall they themselves contribute to the effective R\&D of other firms ("specific R\&D approach"). If $\delta$ falls somewhere between these two extremes, the effective R\&D is a first order homogenous in $x_{i}$.

Hence, the parameter $\delta$ reveals the extent to which a given research program is applicable, and by way of contrast whether it is specific and science-oriented. For higher values of $\delta$ the research programmes should be focused on a relatively fundamental research studies, whereas for lower values of $\delta$ they exhibit the key features of applied research programs.

The effect of collaboration in the implementation of $R \& D$ can be tested via the simulation of Cournot oligopoly game. It has three stages (phases) and is solved through the method of reverse induction. In Phase 3 of the game the two firms choose the optimum level of production at set "sunk" costs. Conspiracy and collusion affecting upon the output levels of production are to be excluded as a possible option. Firms are expected to maximize the volume of the output regardless of their profits, $P$, by choosing the optimal level of production $q_{i}$ :

$$
\max _{q_{i}} P_{i}=\left(p_{i}-k_{i}\right) \cdot q_{i}-x_{i}
$$

Obtained as a final result is the optimal level of production under certain R\&D expenditures in the case of optimization in the Cournot game. In Phase 2 of the game, firms maximize the profits by choosing optimum method and amount of effort to be spared into R\&D activities.

In Phase 1, based on comparing the levels of profits gained as a result of sole or joint investigative R\&D activities, outlined are the incentives offered to the firms for enhancing collaborative undertaking of research projects.

Moreover, as stated in the empirical statistical data, increasing market demand boosts R\&D expenditures of the firms as a whole. This is particularly important in the case of usage of Cournot model, because in it there is profit optimization by the produced quantity criterion.

\section{Inferences drawn}

Given the above theoretical analysis the following general conclusions can be inferred:

$>$ Technological progress depends on the volume of investments in R \& D and on the quality of education in society. 
$>$ Achieving growth depends on the absorption (utilization)capacity and improvement in technology through investments or technology transfer.

$>$ It depends on the institutional environment in the respective economy which is the only one that can stimulate or hinder the efficiency of production performance.

\section{Conclusion}

On the basis of the analysis it can be summed up that the set of categories and methods put forward in the paper acts as a scientific instrumentarium that serves to verify the level of the prearranged (planned) and successfully implemented in the firm research and development activities. At the same time the paper proposes an answer to the question whether it is more efficient for the R\&D activities to be done individually- by every firm or should they be performed in collaboration with other firms. Of utmost importance is also the fact that this is done with utter commitment to crucial complex indicators such as the level of costs and a positive financial result achieved by the given economic entity. The systematized characteristic features of the model make it applicable and effective not only in theory but also in practice.

\section{References}

Aghion, P. and Howitt, P. (1992). A Model of Growth through Creative Destruction. Econometrica, Vol. 60, 323-351

Barro, R.J., Sala-i-Martin, X. (1995). Economic growth. McGraw- Hill, New York

Brander,A. and Spencer, B., Strategic Commitment with R\&D: The Symmetrie Case, The Bell Journal of Economics, Vol. 14, Issue 1 (1983), 225-235

D'Aspremont, C., Jacquemin, A. (1988). Cooperative and noncooperative R\&D in duopoly with spillovers. The American Economic Review 78.

Grossman, G.M. \& Helpman, E. (1991). Innovation and Growth in the Global Economy. The MIT Press Cambridge, Massachusetts, London, England.

Kamien, M. I., Zang, I. (2000). Meet me halfway: research joint ventures and absorptive capacity. International Journal of Industrial Organization 18.

Mankiw, N.G., Romer, D. \& Weil, D. N. (1990). A Contribution to the Empirics of Economic Growth. Working Paper № 3541, National Bureau of Economic Research.

Romer, P.M. (1990). Endogenous technological change. Journal of Political Economy, 98, 5, part II.

Spence, M. 1984. Cost Reduction, Competition and Industry Performance. Economeirica, Econometric Society, vol. 52(1), 101-21

Solow, R.M. (1956). A contribution to the theory of economic growth. Quarterly Journal of Economics, 70, 1, pp. 65-94. 